\title{
SYNTHESIS AND BIOLOGICAL EVALUATION OF SOME SUBSTITUTED AMINO THIAZOLE DERIVATIVES
}

\author{
A. K. PRAJAPATI* AND VISHAL P. MODI \\ Applied Chemistry Department, Faculty of Technology and Engineering, \\ The M. S. University of Baroda, Vadodara-390 001, India. \\ (Received: September 14, 2009 - Accepted: April 26, 2010)
}

\begin{abstract}
Condensation of acetophenone with thiourea in presence of halogen (Iodine) gives 2-amino-4-phenylthiazole (I). 2-Amino-4-phenyl-5-phenylazothizole (II) was prepared by coupling of phenyldiazonium chloride with 2-amino-4-phenylthiazole (I). A series of amide can be synthesized by treatment of appropriate substituted acid chlorides (III) with compound (II) using pyridine as solvent. All the synthesized compounds are characterized by the combination of elemental analysis and standard spectroscopic method. They are screened for anti-bacterial activity against Escherichia coli and Staphylococcus aureus as well as screened for antifungal activity against Aspergillus niger and Apergillus oryzae by cup plate method at $1 \mu \mathrm{g} / \mathrm{mL}$ concentration in DMF. All the synthesized compounds showed moderate to good microbial activity.
\end{abstract}

\section{INTRODUCTION}

It is well known in literature that nitrogen and sulfur containing compounds are essentially used in medical purpose for the treatment of different kinds of fungal and bacterial infections along with treatment of gastric ulcer, cancer etc ${ }^{1,}$ ${ }^{2}$. The organic moiety having nitrogen and sulfur atom results towards higher efficiency against various diseases ${ }^{3}$. Sulfur is capable of forming both $\sigma$ and $\pi$ bonds therefore the studies of their binding interaction with receptor moiety was also an interesting field of research during last few years ${ }^{4,5}$. Thiazole is the five member ring system having two hetero atoms $(\mathrm{S}, \mathrm{N})$ placed in heterocyclic ring at 1,3-positions. Thiazoles are useful structural units in the field of medicinal chemistry and have reported to exhibit a variety of biological activity, thiazole nucleus appears frequently in the structure of various natural products and biologically active compounds, like thiamine (vitamin-B), also in some antibiotics drugs like penicillin, micrococcin ${ }^{8}$, and many metabolic products of fungi and primitive marine animal etc. Number of thiazole derivatives shows good biological as well pharmacological activities like antibacterial and antifungal ${ }^{9}$, anti-inflammatory ${ }^{10}$, analgesic ${ }^{11}$, antitubercular ${ }^{12}$, central nervous system (CNS) stimmulate ${ }^{13}$, anti-HIV ${ }^{14}$, algicidol ${ }^{15}$ etc. Thiazole containing $\mathrm{N}=\mathrm{C}=\mathrm{S}$ moiety have been used as antiphychotics ${ }^{9}$ and antimalarial ${ }^{16}$. 2-Aminothiazole derivatives are well explored as useful clinical agents and some of the derivatives of thiazoles have shown inhibition towards herpes simplex virus ${ }^{17}$. Number of thiazole derivatives has a wide variety of biological activity ${ }^{18-19}$. Some derivatives of 2-aminothiazoles bearing arylazo moiety at position-5 have shown good cytostatic activities ${ }^{20}$. Amides are known to play a pivotal role in molecular recognition, being important components in supramolecular chemical anion sensors ${ }^{21-25}$ technology. Furthermore, in nature, the selective binding for substrate such as anion is achieved via the positional alignment of the amide hydrogen bonds ${ }^{26}$. While plant extracts ${ }^{27}$ and isolated pure nature products 28,29 , have been used for antimicrobial activities, there are few reports of amides as antimicrobial agents $\mathrm{s}^{30,31}$. The present paper deals with the synthesis of some novel amide of 2-amino-4-phenyl-5-phenylazothiazoles with a view to evaluate their biological activity.

\section{EXPERIMENTAL}

\section{Materials:}

The requisite starting materials such as acetophenone, iodine, thiourea, aniline, sodium acetate, sodium nitrite, pyridine, substituted aromatic acids, thionyl chloride were procured from Aldrich Company and used without any further purification. All the solvents were purified and dried by standard method. All melting points were determined in open capillary tube and uncorrected. Purity of compounds was checked by thin layer chromatography (Merck kieselgel $60 \mathrm{~F}_{254}$ pre-coated plates). Microanalysis of the compounds was performed on a Coleman carbon-hydrogen analyzer and the values obtained are in close agreement with those calculated. FTIR spectra were recorded using $\mathrm{KBr}$ pellets, using Shimadzu IR-408 Spectrophotometer. ${ }^{1} \mathrm{H}$ NMR spectra were obtained with Perkin-Elmer R-32 Spectrometer at $300 \mathrm{MHz}$ using tetramethylsilane (TMS) as an internal reference standard. The chemical shift are quoted as $\boldsymbol{\delta}$ (parts per million) downfield from the reference. DMSO-d was used as solvent for all the compounds.
Antibacterial activity ${ }^{33,34}$ : The compounds were tested in-vitro for their antibacterial activity against two microorganisms viz. Escherichia coli and Staphylococcus aureus, which are pathogenic in human beings by cup-plate agar diffusion method.

Antifungal activity ${ }^{33},{ }^{34}$ : The compounds were tested in-vitro for their antifungal activity against Aspergillus niger and Aspergillus oryzae by cupplate agar diffusion method.

The synthetic route to N-(4-phenyl-5-phenylazo-thiazol-2-yl)-substituted arylamide is illustrated in scheme 1 .

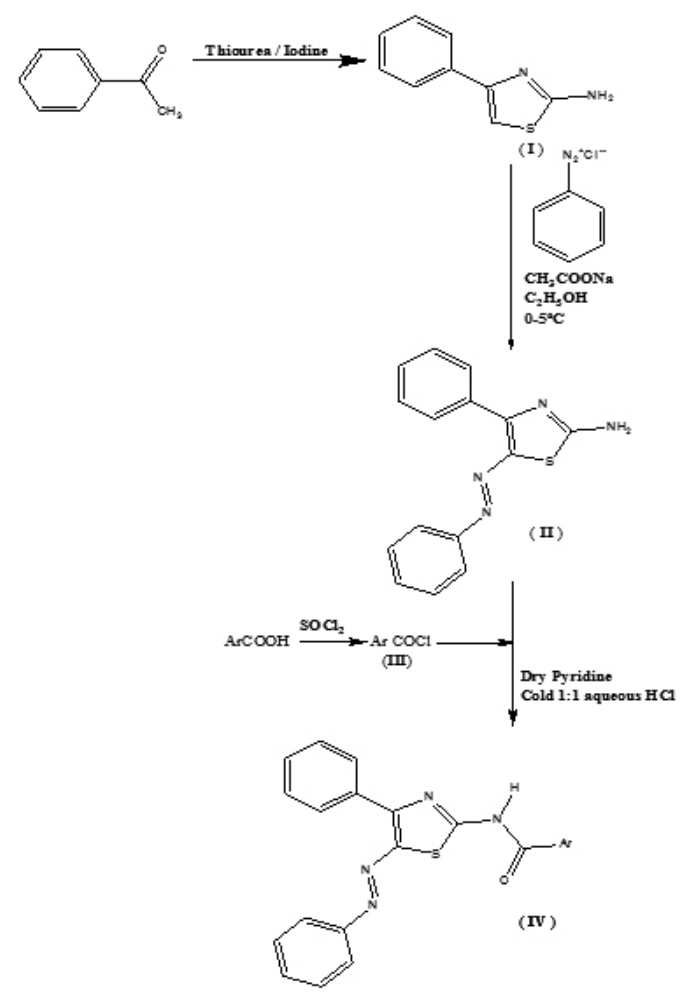

Where Ar = Phenyl, 2-Chlorophenyl, 4-Chlorophenyl, 2,4-Dichlorophenyl, 2-Methylphenyl, 3-methylphenyl, 4-Methylphenyl, 3-Nitrophenyl, 4-Nitrophenyl, 3,5-Dinitrophenyl, 4-Bromo phenyl, Phenylmethyl, 2-Naphthoxy methylene, 4-Phenylphenyl, Cinnamic acid, Nicotin, Isonicotin, 4-Methoxyphenyl, 2-Iodophenyl, 2-Chlorophenylmethylene, 2,4-Dichlorophen- oxymethylene, 4-Chloro-3-nitrophenyl.

Scheme 1: The synthetic route to N-(4-phenyl-5-phenylazo-thiazol-2-yl)substituted arylamide 
2-Amino-4-phenylthiazole (I): 0.1 Mole of acetophenone, 0.1 mole of iodine and 0.2 mole of thiourea was well crushed in crucible. The mixture was taken in $250 \mathrm{~mL}$ round bottom flask and heated at $110^{\circ} \mathrm{C}$ for 24 hours. A reaction mixture was cooled to room temperature and diluted with $100 \mathrm{~mL}$ of water and extracted with ether to remove unreacted iodine and acetophenone. Excess of ether was distilled off. Residue was dissolved in boiling water and filtered off the hot solution. It was allowed to stand for 30 minutes. Make the reaction mixture alkaline (Up to $\mathrm{pH}$ 8-9) using ammonium hydroxide solution. The solid obtained was filtered and washed successively with water ( 2 X 150 $\mathrm{mL})$. The separated solid was crystallized by aqueous ethanol (1:1). M. P.: $148^{\circ} \mathrm{C}$ (Reported ${ }^{32} \mathrm{M}$. P.: $147^{\circ} \mathrm{C}$ ). Yield: $80 \%$.

2-Amino-4-phenyl-5-phenylazothizole (II): An ice-cold solution of 0.02 Mole of sodium nitrite in $25 \mathrm{~mL}$ water was added slowly to solution of 0.02 mole of aniline in $15 \mathrm{~mL}$ of $\mathrm{HCl}$ at $0-5^{\circ} \mathrm{C}$. To well cool solution of 0.02 mole of 2-amino-4-phenylthiazole and 15 gms of sodium acetate in ethanol was gradually added the diazonium salt solution with stirring and cooling $\left(0-5^{\circ} \mathrm{C}\right)$. The reaction mixture was stirred at this temperature for 2 hours and then diluted with cold water. The separated solid was collected by filtration. The solid obtained was washed successively with water $(2$ X $150 \mathrm{~mL})$. The separated solid was crystallized by aqueous ethanol $(1: 1)$. M. P.: $175^{\circ} \mathrm{C}$. Yield: $70 \%$. Elemental Analysis: Calculated for $\mathrm{C}_{15} \mathrm{H}_{12} \mathrm{~N}_{4} \mathrm{~S}$ : C, 64.28; H, 4.28; N, $20.00 \%$. Found: C, 64.15; H, 4.11; N, $19.79 \%$. FTIR spectrum (KBr) $v_{\text {mor }} / \mathrm{cm}^{-1}: 3200$ $\left(-\mathrm{NH}_{2}\right), 1650(-\mathrm{N}=\mathrm{N}-)$ 1525, 1475, 1340, 1250, 1200, 1075, 1000 and 790 (st. of thiazole nucleus). ${ }^{1} \mathrm{H}$ NMR spectrum (DMSO-d $\mathrm{d}_{\mathrm{f}}$ : $\boldsymbol{\delta}$ 7.42-7.90 (m, 8H, ArH), $8.10\left(\mathrm{~d}, 2 \mathrm{H}, \mathrm{Ar}-\mathrm{H}\right.$ at C-2' and C-6'), 8.7 (br, $\left.2 \mathrm{H},-\mathrm{NH}_{2}\right)$

Aromatic acid chlorides (III): A mixture of 0.01 mole of substituted aromatic acid was added to $15 \mathrm{~mL}$ of thionyl chloride. It was refluxed on water bath till the evolution of hydrogen chloride gas ceased. Excess of thionyl chloride was distilled off under reduced pressure and the acid chloride left behind as a residue was used in next reaction without further purification.

N-(4-phenyl-5-phenylazo-thiazol-2-yl)-substituted arylamide (IV): 0.01 Mole of 2-amino-4-phenyl-5-phenylazothizole (II) was dissolved in $10 \mathrm{~mL}$ dry pyridine and a cold solution of an appropriate 0.01 mole substituted aromatic acid chloride (III) in dry pyridine was added slowly to it with constant stirring in an ice bath. The mixture was allowed to stand over night at room temperature and then heated on water bath for half an hour. It was acidified with cold 1:1 aqueous hydrochloric acid. The solid obtained was filtered and washed successively with water $(2 \times 50 \mathrm{~mL})$, saturated solution of sodium bicarbonate $(2 \times 50 \mathrm{~mL})$ and water $(2 \times 30 \mathrm{~mL})$. The crude material obtained was chromatographed on silica gel (100-200 mesh) using mixture of ethyl acetate and hexane (20:80) as eluent. Removal of solvent from the eluate afforded a solid material, which was crystallized repeatedly from appropriate solvent. The purity of all these compounds was checked by thin layer chromatography (Merck kieselgel 60F254 pre-coated plates).

\section{RESULTS AND DISCUSSION}

Reaction of acetophenone, thiourea and halide gives 2-amino-4phenylthiazole (I). Halide was used for cyclisation purpose. We can use chlorine or bromine or iodine. Here, we had used iodine for cyclisation because it is easy to handle. In second step, diazonium salt of aniline was coupled with 2-amino-4-phenylthiazole using sodium acetate and ethanol as solvent. Sodium acetate acts as buffer, which can control the $\mathrm{pH}$ of solution. Coupling occurs at neutral $\mathrm{pH}$. So finally we get a product 2-amino-4-phenyl-5-phenylazothizole (II). Different substituted aromatic acid chlorides (III) were prepared by the reaction of the corresponding aromatic acid with excess of thionyl chloride by heating on a water-bath till the evolution of hydrogen chloride gas ceased. Finally, the target derivatives were obtained when 2-amino-4-phenyl-5phenylazothizole (II) was condensed with appropriate substituted aromatic acid chlorides (III) by employing Schotten-Bauman synthesis protocol.

The elemental analyses of all the compounds were found to be satisfactory. The synthesized compounds were characterized by FTIR and ${ }^{1} \mathrm{H}$ NMR spectroscopy. The FTIR spectrums showed absorption bands in the region of $v / \mathrm{cm}^{-1} 3350$ to 3400 for (-NH) stretching, $1575-1590$ for (-NH-) bending, $1640-1650$ for $(-\mathrm{C}=\mathrm{O}-), 1625$ for $(-\mathrm{N}=\mathrm{N}-), 1330-1350$ for $(-\mathrm{C}=\mathrm{S}-)$ stretching, 1200 for (-C-O-) bending and 1000 as well as 790 due to stretching of thiazole nucleus . In the ${ }^{1} \mathrm{H}$ NMR spectrum, aromatic protons appeared in the region of $\boldsymbol{\delta} 7.47-8.38$, while amide proton appeared as a singlet in the region of $\boldsymbol{\delta} 13.13$ 13.50. The spectral data of all the compounds were found to be consistent with their molecular structure. The data of elemental analysis, FTIR and ${ }^{1} \mathrm{H}$ NMR of few representative members with general structural formula are given in Table 1.

Table 1: Elemental analysis, IR and ${ }^{1} \mathrm{H}$ NMR data of prepared thiazole derivatives.

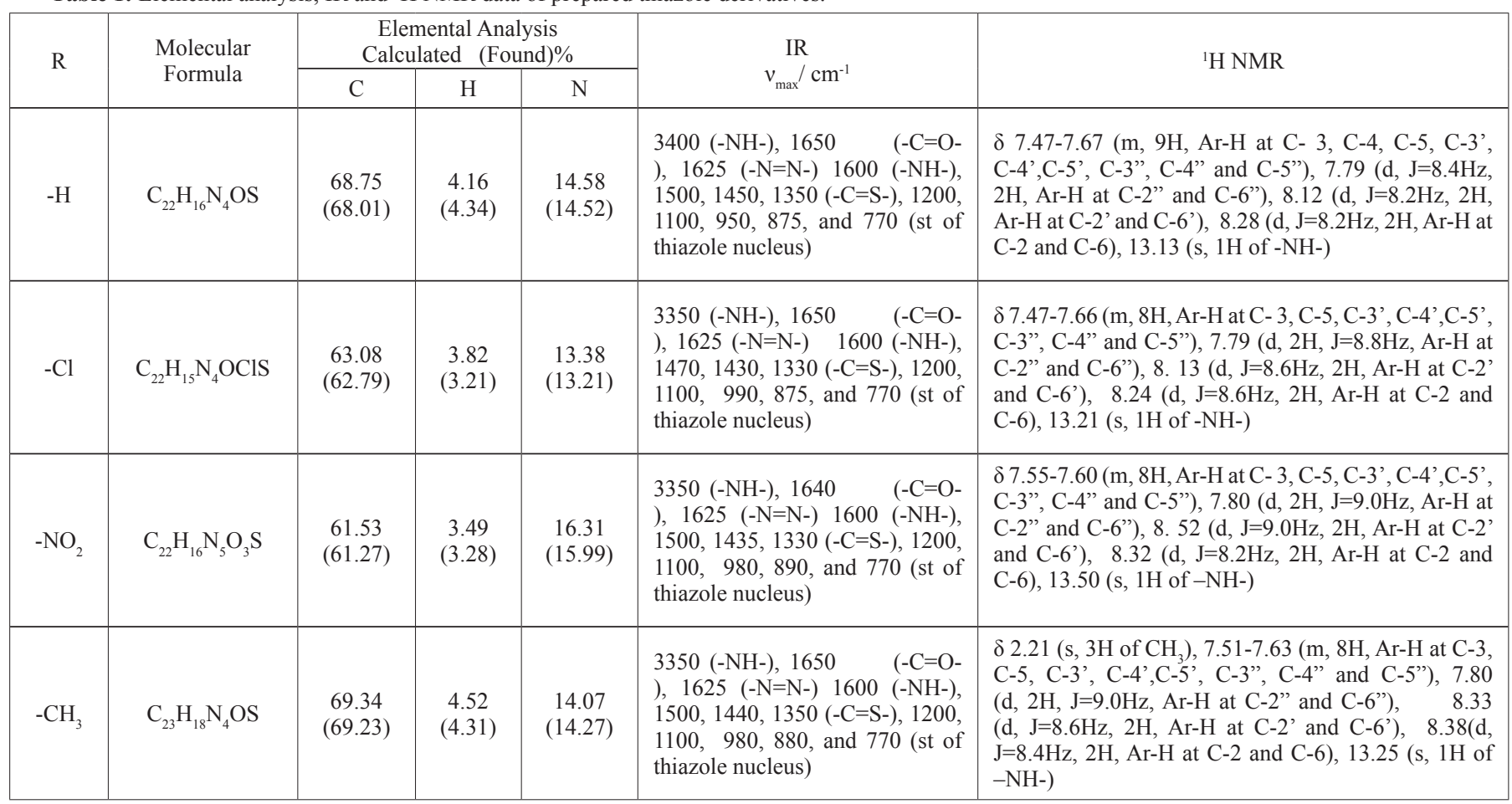


The solvent for crystallization and the physical data of all the prepared thiazole derivatives are given in table 2.

All compounds were screened for antibacterial activity against $E$. coli and $S$. aureus by cup plate method ${ }^{21-22}$. For anti bacterial activity, we had taken 20 gms of Luria-Bertani broth (Hi media M-575) and 25 gms of agar-agar in 1000 $\mathrm{mL}$ distilled water and heated till dissolved. Then, the mixture was sterilized by autoclaving at $15 \mathrm{lbs}$ pressure and $121^{\circ} \mathrm{C}$ for 15 minutes. Here, agar-agar was used to solidify the solution. After that, six petri dishes having flat bottom were taken and filled with about $18 \mathrm{~mL}$ of above solution. The plates were overlaid with $4 \mathrm{~mL}$ soft agar-agar containing $0.1 \mathrm{~mL}$ test culture. Four wells were bored on each plate with $8 \mathrm{~mm}$ diameter cork bore aseptically. Now we had dissolved the compound in DMF having $1000 \mathrm{ppm}$ concentration and added $0.1 \mathrm{~mL}$ of testing solution into each well. This solution was allowed to diffuse at $4^{\circ} \mathrm{C}$. After 20 minutes diffusion, the plate was incubated at $37^{\circ} \mathrm{C}$ for over night. After incubation, we observed the zone of inhibition and measured the diameter of the zone. For anti fungal activity, we had taken 20 gms Sabouraud dextrose instead of Luria-Bertani broth and followed the same procedure as above. All the synthesized compounds showed good antimicrobial activity (Table 2). From the table 2, we can see that bromo, hydrogen, iodo substituted derivatives show moderate activity while methyl substituted derivatives show good activity against $E$. coli (Gram-negative bacterium). We can see that chloro, nitro and methyl derivatives show good activity for S. aureus (Grampositive bacterium). All the compounds give same activity against $A$. niger and A. oryzae. All the synthesized compounds show moderate to good activity due to presence azo and aminde linkages as well as thiazole moiety.

Table 2: Physical and antimicrobial activity data of prepared thiazole derivatives.

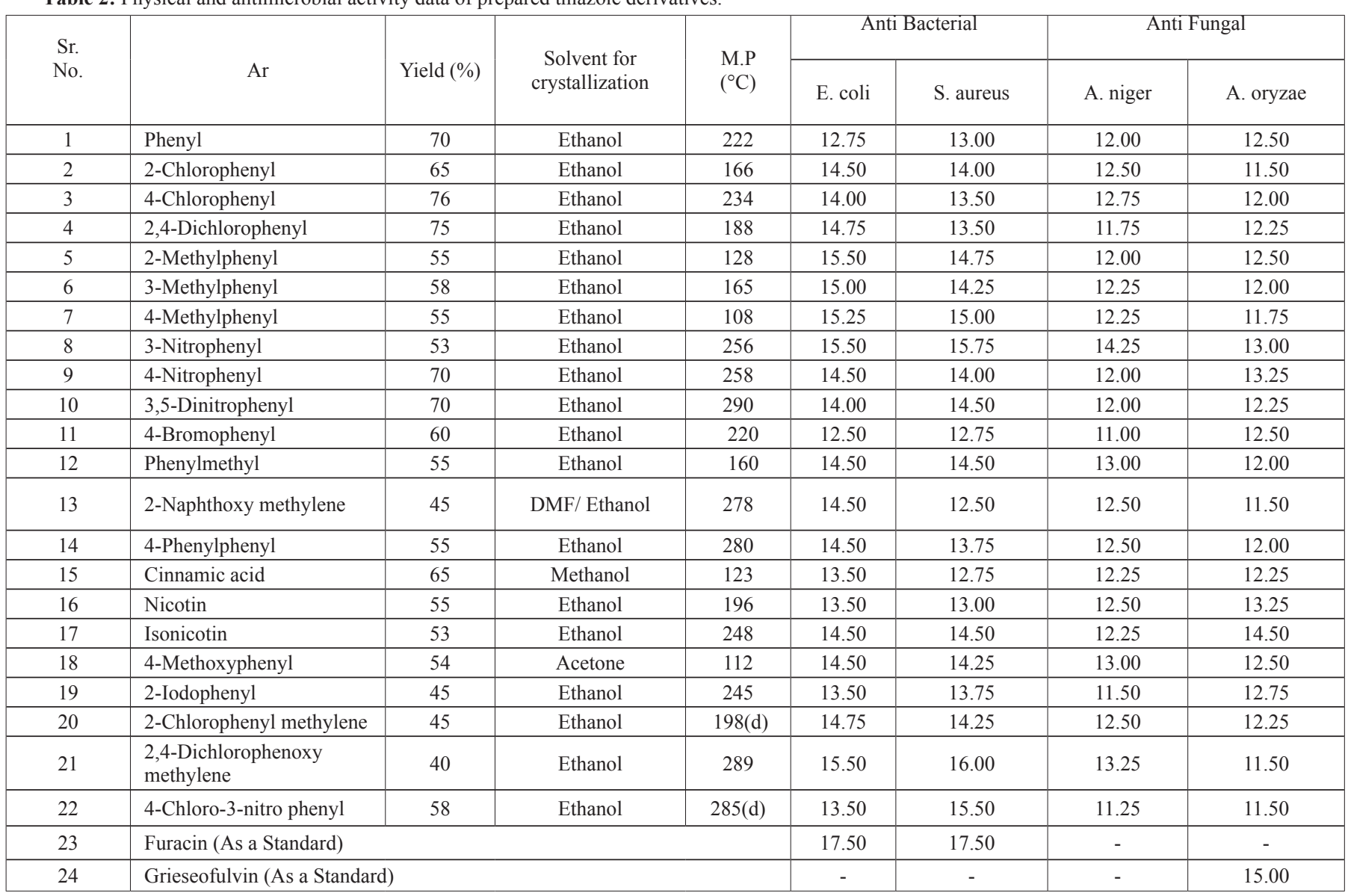

(d): decompose

\section{CONCLUSION}

All the newly synthesized amino thiazole derivatives with amide linkage have good anti-bacterial and anti-fungal activity. Therefore, they can be used for the development of new drugs for treatment of bacterial and fungal diseases.

\section{REFERENCES}

1.- A. Bishayee, R. Karmaker, A. Mandal, S. N. Kundu, M. Chaterjee, Eur. J. Cancer. Prev. 6, 58, (1997).

2.- T. F. Cruz, A. Morgon, W. Min, Mol. Biochem. 153, 161, (1995).

3.- C. R. Chitamber, J. P. Wereley, J. Biol. Chem. 272, 12151, (1997).

4.- G. Barone, M. C. Ramusino, R. Barbieri, G. L. Manna, J. Mol. Struct. 469, 143, (1999).

5.- R. Kant, K. Singhal, S. K. Shukla, K. Chandrashekar, A. K. Saxena, A. Ranjan, P. Raj, Phosphorus, sulfur and silicon. 183, 2029, (2008).
6.- D. Luanicer, L. A. Mitscher, The Organic Chemistry of Drug Synthesis, John Wiley and Sons, New York, 1980.

7.- R. K. Bansal Heterocyclic Chemistry, New Age International Publisher, New Delhi, 2003.

8.- M. J. Rogers, E. Cundliffe, T. F. Mccutchan, Antimicrobial agents and chemotherapy. 42, 715, (1966).

9.- S. R. Pattan, N. S. Dighe, S. A. Nirmal, A. N. Merekar, R. B. Laware, H. V. Shinde, D. S. Musmade, Asian J. Research Chem. 2(2), 196, (2009).

10.- R. N. Sharma, F. P. Xavier, K. K.Vasu, S. C. Chaturvedi, S. S. Pancholi, Journal of enzyme inhibition and medicinal chemistry. 24, 890, (2009).

11.- I. Argyropoulou, A. Geronikaki, P. Vicini, F. Zanib, Arkivoc. VI, 89, (2009).

12.- H. D. Trautman, L. M. Longe, J. Am. Chem Soc. 70, 3436, (1948).

13.- A. R. Surray, J. Am. Chem Soc. 71, 3354, (1949).

14.- P. Bhattacharya, J. T. Leonard, K. Roy, Bioorganic and Medicina Chemistry 13, 1159, (2005). 
15.- A. Alemagna, T. Bacchetti, P. Beltrame, Tetrahedron. 24, 3209 (1968).

16.- H. N. Karade, B. N. Acharya, M. Sathe, M. P. Kaushik, Medicina Chemistry Research 17, 19, (2008).

17.- (a) F. C. Spector, L. H. Liang, G. M. Sivaraja, M. G. Peterson, Journal of virology. 72(9) 6979, (1998).

18.- M. M. Ghorab A. 1. El-Batal, Boll. Chim. Farm. 141(2), 110, (2002).

19.- V. H. Bhaskar, M. Kumar, B. Sangameswaran, B. R. Balakrishnan, Rasayan J. Chem. 1, 218, (2008).

20.- D. G. Craciunescu. A. Furlani, V. Scarcia, A. Doadrio, Biological Trace Element Research 8, 251, (1985).

21.- A. Mishra, R. K. Singh, S. Singh, A. Mishra, M. Kumar, R. Kant, R. S. Thakur, Internation J. of Pharma. Analysis. 1, 1, (2009).

22.- R. C. Jagessar, D. Rampersaud, New York Science J., 1, 22, (2008).

23.- P. D. Beer, M. G. B. Drew, C. Hazelwood, D. Hesek, J. Hodacova, S. E. Stokes, J. hem. oc. hem. Commun. 229, 1993.

24.- P. D. Beer, M. G. B. Drew, D. Hesek, R. Jagessar, J. Chem. Soc., Chem. Comm. 1187, 1995.

25.- P. D. Beer, M. G. B. Drew, R. Jagessar, J. Chem. Soc., Dalton Trans. 881, 1997.

26.- J. E. Stokes, G. L. Ridgway, Clinical Bacteriology, Ch. 7, Edward Arnold Publishers, $5^{\text {th }}$ Edition, 1980.
27.- A. Rojas, L. Hernandez, R. Pereda-Miranda, R. Mata, J. Ethanopharmacol. 35, 275, (1992)

28.- O. Silva, A. Duarte, J. Cabrita, M. Pimentel, A. Diniz, E. Gomes, $J$. Ethanopharmacol. 50, 55, (1996).

29.- V. Navara, M. L. Villarrea, G. Rojas, X. Lozoya, J. Ethanopharmacol. 50, 143, (1996).

30.- B. Narasimhan, D. Belsare, A. Dhake, Eur. J. Med. Chem. 39, 827, (2004).

31.- B. Priya, S. N. Swamy, K. S. Rangapa, Bio. Org. Med. Chem. 13, 7 , (2005).

32.- R. M. Dodson, L. Carroll King, J. Am. Chem Soc. 67, 2242, (1945).

33.- R.W. Bauer, M. D. K. Kirby, J. C. Sherris, M. Turck, American J. Clinical Pathology. 45, 49, (1966).

34.- A. L. Barry, Biol. Abstr., 64, 257, (1976).

\section{ACKNOWLEDGEMENT}

We are thankful to the Dean, Faculty of Technology and Engineering, and Head, Applied Chemistry Department, for providing the research facilities. We are also thankful to Dr. G. Archana, Microbiology Department, Faculty of Science, The M. S. University of Baroda, Vadodara for useful discussion about microbial activity. 